Review Article

\title{
Acute Kidney Injury following Cardiopulmonary Bypass: A Challenging Picture
}

\author{
Dianxiao Liu $\mathbb{D}^{1,2}$ Baohui Liu $\mathbb{D}^{1},{ }^{1}$ Zhenxing Liang $\mathbb{D},{ }^{3}$ Zhi Yang $\mathbb{D},{ }^{2}$ Fangjian $M a \mathbb{D}^{4}$ \\ Yang Yang ${ }^{2},{ }^{2,5}$ and Wei Hu iD ${ }^{2}$ \\ ${ }^{1}$ Department of Cardiac Surgery, Binzhou Medical University Hospital, 661 Huanghe 2nd Road, Binzhou 256603, China \\ ${ }^{2}$ Key Laboratory of Resource Biology and Biotechnology in Western China, Ministry of Education, Faculty of Life Sciences, \\ Northwest University, 229 Taibai North Road, Xi'an 710069, China \\ ${ }^{3}$ Department of Cardiothoracic Surgery, The First Affiliated Hospital of Zhengzhou University, 1 Jianshe East, \\ Zhengzhou 450052, China \\ ${ }^{4}$ PLA Unit 93307, 118 Honghu North Street, Shenyang 110141, China \\ ${ }^{5}$ Xi'an Key Laboratory of Cardiovascular and Cerebrovascular Diseases, Xi'an No.3 Hospital, School of Life Sciences and Medicine, \\ Northwest University, 10 Fengcheng Three Road, Xi'an 710021, China
}

Correspondence should be addressed to Baohui Liu; baohuiliubz@163.com, Yang Yang; yang200214yy@163.com, and Wei Hu; weihu555@126.com

Received 31 August 2020; Revised 2 February 2021; Accepted 18 February 2021; Published 9 March 2021

Academic Editor: Jayeeta Ghose

Copyright (C) 2021 Dianxiao Liu et al. This is an open access article distributed under the Creative Commons Attribution License, which permits unrestricted use, distribution, and reproduction in any medium, provided the original work is properly cited.

Recent studies have recognized several risk factors for cardiopulmonary bypass- (CPB-) associated acute kidney injury (AKI). However, the lack of early biomarkers for AKI prevents practitioners from intervening in a timely manner. We reviewed the literature with the aim of improving our understanding of the risk factors for CPB-associated AKI, which may increase our ability to prevent or improve this condition. Some novel early biomarkers for AKI have been introduced. In particular, a combinational use of these biomarkers would be helpful to improve clinical outcomes. Furthermore, we discuss several interventions that are aimed at managing CPB-associated AKI, may increase the effect of renal replacement therapy (RRT), and may contribute to preventing CPB-associated AKI. Collectively, the conclusions of this paper are limited by the availability of clinical trial evidence and conflicting definitions of AKI. A guideline is urgently needed for CPB-associated AKI.

\section{Introduction}

Cardiopulmonary bypass $(\mathrm{CPB})$ is a form of extracorporeal circulation that temporarily replaces the function of the heart and lungs during surgery to maintain the circulation of blood and oxygen in the patient, which has benefited thousands of patients since its introduction nearly 60 years ago $[1,2]$. The 2017 Heart Disease and Stroke Statistics from the American Heart Association reported outcomes for approximately 400,000 patients undergoing cardiac surgical procedures each year, and more than $80 \%$ of these procedures were performed using $\mathrm{CPB}$ [3]. However, $\mathrm{CPB}$ is not a benign procedure, and a number of associated problems remain, including hemolysis
[4], capillary leak syndrome [5], and acute kidney injury (AKI) [6-8]. AKI occurs in $18.2 \%$ to $30 \%$ of patients who undergo CPB surgery $[7,9-11]$ and is an important predictor of morbidity and mortality after cardiac surgery [12-15].

$\mathrm{AKI}$ is defined as the rapid deterioration of kidney function within 48 hours after the initiating event $[16,17]$ and exerts a separate independent effect on the risk of death $[18,19]$. Generally, AKI could be caused by a decrease in the renal blood flow, renal inflammation, or pigment nephropathy resulting from any reason. Septic shock and $\mathrm{CPB}$ surgery are the two of the most common factors that contribute to AKI [20]. In patients undergoing CPB, AKI is associated with poor outcomes, prolonged hospital stays, 
increased mortality, and stroke $[6-8,21,22]$. In particular, CPB-associated AKI was associated with an 8.2-fold increase in in-hospital mortality [11].

Until a decade ago, a uniform definition of AKI was lacking, creating problems in comparing published results. In 2007, the AKI Network (AKIN) modified the risk, injury, failure, loss, end-stage renal disease (RIFLE) criteria established in 2004 by including an absolute change in the serum creatinine ( $\mathrm{sCr}$ ) level, which also decreased the time over which AKI was to be diagnosed from 7 days to 48 hours [16, 17]. The recent 2012 Kidney Disease: Improving Global Outcomes (KDIGO) criteria combined RIFLE and AKIN, providing clear guidelines for the timing of AKI ascertainment and severity staging based on changes in sCr levels and urine output [23]. Based on accumulating evidence from meta-analyses, a consistency of prognostic estimates exists across AKI definitions. Notably, if the expected hospital stay is less than 7 days, the AKIN definition may be the most suitable [7].

Renal replacement therapy (RRT) is necessary for treating CPB associated-AKI [24], which is experienced by approximately $1 \%$ to $2.9 \%$ of all patients who undergo CPB surgery $[9,21]$. Additionally, the use of RRT is a marker of early mortality and long-term mortality [25], similar to CPB-associated RRT $[7,21,26]$. The thirty-day mortality rate of patients with CPB-associated AKI who require RRT is $42 \%$ [21]. An estimate of the variation in the risk factors associated with clinical outcomes is needed to contribute to the prevention of CPB-associated AKI [7]. The detection of biomarkers is useful to prevent CPB-associated AKI [27]. We must improve our understanding of the mechanisms involved in CPBassociated AKI to prevent this disease and to develop comprehensive interventions for managing $\mathrm{CPB}$-associated $\mathrm{AKI}$ when it occurs.

The focus of this review is to provide a comprehensive evaluation of CPB-associated AKI. First, the risk factors for $\mathrm{CPB}$-associated AKI are summarized. Then, we present a review of the methods currently used to manage AKI following $\mathrm{CPB}$, including RRT and other interventions. Finally, potential directions for future $\mathrm{CPB}$-associated AKI are discussed. Collectively, the compiled information should serve as a comprehensive repository of the evidence that is currently available in this area, which should aid in the design of future studies. This review should contribute to the prevention and management of CPB-associated AKI.

\section{Risk Factors for Acute Renal Dysfunction following Cardiopulmonary Bypass}

Generally, the relative risk of AKI has decreased by $8 \%$ per year beginning in 2000 [28], and AKI-associated mortality is also decreasing [29]. Several risk factors have been identified to predict the development of CPB-associated AKI. The risk factors are classified as patient-related and procedurerelated factors, and a comprehensive understanding of these factors and AKI should further contribute to our ability to control CPB-associated AKI.

2.1. Patient Conditions. An older age is an independent risk factor for developing AKI $[30,31]$; for example, an age $>70$ years is an independent risk factor for postoperative AKI, with a relative risk ranging from 2 to 2.232 [95\% confidence interval (CI), 1.326-3.757; $P<0.005][32,33]$. Female sex is another established independent patient-related risk factor for the development of CPB-associated AKI. Most meta-analyses have revealed that women are more likely than men to develop AKI postoperatively [odds ratio (OR), 1.21; 95\% CI, 1.09-1.33; $P<0.001$ ] [34]. A smoking history is also an independent factor (OR, 2.008; 95\% CI, 1.144-3.524; $P=0.0151)$ [34]. A left ventricular ejection fraction $(\mathrm{LVEF})<35 \%$ was shown to be an independent risk factor for postoperative AKI (OR, 1.25; 95\% CI, 1.01-2.2; $P=0.01$ ) [33]. Furthermore, controlled clinical trials revealed a high risk of the development of AKI in children with congenital heart disease [26, 35, 36], with reported incidences ranging from $29 \%$ to $86 \%$ [36].

The presence of any extent of preoperative renal dysfunction (which is defined as a sCr level $\geq 1.2 \mathrm{mg} / \mathrm{dL}$ ) increases the risk of $\mathrm{CPB}$-associated $\mathrm{AKI}$ compared with the very low risk $(<2 \%)$ for a patient with normal renal function under the same conditions [37, 38]. The preoperative estimated glomerular filtration rate (eGFR) is the best indicator of postoperative renal dysfunction. Based on several lines of evidence, a baseline eGFR $<60 \mathrm{~mL} / \mathrm{min} / 1.73 \mathrm{~m}^{2}$ is associated with an increased risk of CPB-associated AKI [38-42]. Furthermore, diabetes is also suggested to be independently associated with AKI [43], which may result from the deterioration of already borderline renal function $[44,45]$. A decreased eGFR and borderline renal function may therefore be collectively associated with the incidence of CPB-associated AKI. Patientrelated factors must be carefully evaluated to obtain a better risk stratification. Preventive approaches, such as glucose control, are suggested to be administered to reduce the burden of AKI and prevent CPB-associated AKI [33, 43]. Thoughtful and individualized decisions regarding the treatment of patients with multiple risk factors are necessary.

2.2. Creatinine. An elevated preoperative sCr level is the most significant predictive risk factor for postoperative AKI following CPB described to date [46, 47], as also evidenced by higher peak postoperative creatinine levels within $48 \mathrm{~h}$ of arrival in the intensive care unit (ICU) associated with persistent AKI [32]. The risk of AKI is increased 4.8-folds for each $1 \mathrm{mg} / \mathrm{dL}$ increase in the sCr level [38]. The patient's risk for postoperative dialysis after AKI reaches $10-20 \%$ with a baseline creatinine concentration of $2.0-4.0 \mathrm{mg} / \mathrm{dL}$ and approximately $25 \%$ when the baseline creatinine concentration is greater than $4.0 \mathrm{mg} / \mathrm{dL}$ [48]. In addition to inducing the development of AKI, preoperative creatinine levels greater than $2.5 \mathrm{mg} / \mathrm{dL}$ increase the risk of mortality and prolong the length of hospital stay following CPB surgery [49]. Collectively, these data indicate the value of monitoring and focusing on increased $\mathrm{sCr}$ levels throughout the perioperative period.

2.3. Genetic Polymorphisms. The clinical predictors and biochemical markers that have been identified as being associated with the development of AKI only partially explain the individual risk [20]. Another tool for predicting the risk of AKI and improving individualized patient care is focused on identifying the genetic risk factors that might be involved 
in the development of AKI. Several genetic polymorphisms have been identified to play roles in the occurrence and progression of AKI after cardiac surgery with $\mathrm{CPB}$. As shown in the study by Leaf et al. [50], patients with a longer allele genotype in the heme oxygenase-1 (HO-1) gene (HMOX1) promoter exhibited an increased risk of postoperative AKI after cardiac surgery with $\mathrm{CPB}(\mathrm{OR}, 1.26$; $95 \% \mathrm{CI}$, 1.05$1.503 ; P=0.01)$. This finding is consistent with heme toxicity as a pathogenic feature of cardiac surgery-associated AKI, suggesting the potential of $\mathrm{HO}-1$ as a therapeutic target in the future. Additionally, Popov et al. [51] examined SNP rs1617640 in the promoter of the erythropoietin (EPO) gene using DNA sequencing and found that the risk allele rs1617640 (T) plays a role in the development of AKI after cardiac surgery with $\mathrm{CPB}$. Patients with the TT risk allele produced increased concentrations of EPO and required more frequent acute RRT. A patient's ability to produce more EPO may be associated with thromboembolic events and therefore affects morbidity and mortality after CPB. Furthermore, Stafford-Smith et al. [52] identified two novel susceptibility loci (chr3p21.6 and BBS9) for AKI after cardiac surgery with $\mathrm{CPB}$. These data provide candidate regions for future genetic research on cardiac surgery-associated AKI and may ultimately contribute to improvements in preoperative screening and the development of novel prevention and intervention options to decrease AKI and associated morbidity and mortality. Despite the substantial progress, formidable challenges regarding the widespread clinical application of genetic testing remain due to its high cost and timeconsuming process.

2.4. Hemoglobin Concentration. Based on accumulating evidence, the hemoglobin concentration measured during $\mathrm{CPB}$ surgery is associated with the incidence of AKI after CPB surgery. According to a study by Haase et al. [11], a decreased hemoglobin concentration during $\mathrm{CPB}$ surgery is an independent risk factor for AKI, with an effect cut-off value of $<9 \mathrm{~g} / \mathrm{dL} \quad(<5.6 \mathrm{mmol} / \mathrm{L}) \quad(\mathrm{OR}, 1.16$ per $1 \mathrm{~g} / \mathrm{dL}$ decrease; 95\% CI, 1.05-1.31; $P=0.018)$, which is not altered by systemic arterial oxygen saturation and pressure values. Other studies also support that the low hemoglobin concentration even within the normal range, as well as the nadir hemoglobin level, is associated with increased incidence of CPB-associated AKI $[53,54]$. Strategies that improve the hemoglobin concentration, such as the conservative use of red blood cell (RBC) transfusion, are recommended, since circulating free iron-mediated nephrotoxicity with hemolysis and free hemoglobin are likely to lead to AKI in patients undergoing cardiac surgery with $\mathrm{CPB}$. However, the volume of transfused RBCs represents a specific additional risk factor if this treatment is administered to patients with hemoglobin levels $>8 \mathrm{~g} / \mathrm{dL} \quad(>5 \mathrm{mmol} / \mathrm{L})$. Therefore, future studies should further investigate if modified blood conservation strategies or the restriction of RBC transfusion to patients with a hemoglobin concentration $<8 \mathrm{~g} / \mathrm{dL}(<5 \mathrm{mmol} / \mathrm{L})$ will improve renal outcomes. Is increasing the hemoglobin concentration with an EPO supplement and other methods more beneficial for patients with decreased hemoglobin concentrations?
2.5. Hemodilution. Hemodilution is another independent risk factor for developing renal injury (including AKI), with the lowest predictive cut-off value being a hematocrit $<24 \%$ [37]. A multivariate analysis revealed a $7 \%$ increase in the relative risk of $\mathrm{AKI}$ per $1 \%$ decrease in the nadir hematocrit value during $\mathrm{CPB}$ [28]. Hemodilution-induced renal injury was exacerbated when $\mathrm{CPB}$ was prolonged by the use of intraoperative packed RBC transfusions [37], suggesting a conflict between maintaining adequate hydration and using extended diuretic therapy and avoiding hemodilution [35]. Improvements in oxygen delivery conditions may contribute to solving this problem [55]. Moreover, the hemodilutionrelated AKI risk has been limited by many improvements to $\mathrm{CPB}$ technology that have been proposed in the past decade, including the redesign of the circuit to minimize the volume, the use of retrograde autologous priming, and the management of intraoperative fluid administration [28].

Notably, Svenmarker et al. [56] observed a decrease in the $\mathrm{sCr}$ concentration following CPB-induced hemodilution, which significantly hampered the creatinine-based diagnosis of AKI. Thus, the use of sCr levels to monitor renal function during $\mathrm{CPB}$ should be employed with caution to avoid underestimating the risk of AKI.

2.6. Oxygen Delivery. According to an increasing number of studies, the kidneys may suffer from an imbalance between the amount of oxygen that is available and the amount of oxygen they need during CPB [57]. As shown in the study by Ranucci et al. [58], the best predictor for AKI and peak postoperative $\mathrm{sCr}$ levels was the lowest oxygen delivery during $\mathrm{CPB}$, with a critical threshold of $<272 \mathrm{~mL} / \mathrm{min} / \mathrm{m}^{2}$. The effects of decreased hemoglobin concentrations and hemodilution on the incidence of AKI during $\mathrm{CPB}$ are potentially attributed to a decrease in the oxygen carrying capacity [57]. A decreased oxygen carrying capacity related to hemodilution might be compensated by increasing $\mathrm{CPB}$ oxygen delivery using an adequately increased pump flow. Interestingly, in patients with severe anemia $(<25$ th percentile for the lowest hemoglobin level), the independent effect of hypotension ( $>75$ th percentile of the area under the curve for MAP $<50 \mathrm{mmHg}$ ) on AKI was pronounced [OR, 3.36 (95\% CI 1.34-8.41); $P=$ 0.010 ] [11]. After correcting for the need for transfusions, only the lowest level of oxygen delivery remained an independent risk factor for AKI during CPB [58]. Excursions of mean arterial blood pressure that were below the limit of autoregulation were independently associated with AKI, but not the absolute mean arterial blood pressure [43]. Inadequate oxygen delivery during $\mathrm{CPB}$ was associated with lactate production, and hyperlactatemia appeared when oxygen delivery decreased below $260 \mathrm{~mL} / \mathrm{min} / \mathrm{m}^{2}$ under normothermic conditions [59]. Thus, monitoring the cerebral oximetry index using nearinfrared spectroscopy signals may represent a novel method for precisely guiding procedures aimed at maintaining a mean arterial blood pressure target during $\mathrm{CPB}$, which further reflects the level of renal perfusion $[43,60]$. In addition, pump flow should be coupled with hematocrit monitoring to avoid a decrease below the critical level of oxygen delivery. However, the extent to which the dose for oxygen delivery can be decreased remains to be estimated. 
Different interventions aimed at preserving oxygen delivery during $\mathrm{CPB}$ have been reported to exert beneficial effects on goal-directed perfusion applications, and the incidence of AKI has been reduced from $5.8 \%$ to $3.1 \%$ [28]. Four elements of the formula for oxygen delivery under $\mathrm{CPB}$, including pump flow, hemoglobin, oxygen saturation, and arterial oxygen tension, can be carefully monitored and properly modified, thus promoting the likelihood of adequate oxygen delivery [61]. The ability to maintain oxygen delivery and satisfy all these components requires cooperation and coordination among the members of the cardiac surgical team. In addition, Bennett et al. [62] compared the average oxygen delivery during bypass for a miniaturized $\mathrm{CPB}$ and for a conventional $\mathrm{CPB}$ circuit and did not observe differences in the average oxygen delivery. The association between oxygen delivery and postoperative changes in plasma creatinine levels was clear in both groups. However, further studies are needed to determine whether a particular cohort of patients benefits (or are put at risk) from each method of CPB. Furthermore, oxygen preconditioning has been shown to prevent nephropathy in patients [63] and AKI [64], renal ischemia/reperfusion injury [65], and nephrotoxicity in rats [66]. Accordingly, the use of hyperbaric oxygen therapy and oxygen preconditioning may be beneficial for preventing AKI following CPB.

2.7. Use of Angiographic Examinations. Contrast agent has been suggested to induce AKI in patients undergoing coronary angiography or percutaneous coronary interventions [44]. Ranucci et al. [28] showed that a policy restricting angiographic examination on the day of operation reduced the AKI rate from $4.8 \%$ to $3.7 \%$. Performing cardiac surgery on the day of cardiac catheterization and using a higher dose of contrast agent were independently associated with an increased risk of postoperative AKI [67]. Interestingly, the administration of contrast to cyanotic patients with $\mathrm{CHD}$ within the $48 \mathrm{~h}$ prior to $\mathrm{CPB}$ was not an additional risk factor for developing AKI [46]. In conclusion, the angiographic examination may be not associated with an increased AKI rate. However, delaying cardiac surgery for more than $24 \mathrm{~h}$ after exposure to contrast agents (when feasible) and minimizing the use of contrast agents may significantly decrease the incidence of postoperative AKI in patients undergoing $\mathrm{CPB}$ surgery.

2.8. Time on $C P B$. Time on $\mathrm{CPB}$ was associated with the risk of developing AKI requiring dialysis [41, 68-71] In one study, after adjusting for confounders, the association between the time on $\mathrm{CPB}$ and $\mathrm{AKI}$ requiring dialysis lost its statistical significance [71]. Thus, an accurate risk assessment might be more important than the time on CPB in predicting the occurrence of AKI requiring dialysis. Nonetheless, the $\mathrm{CPB}$ time should be minimized to the greatest extent possible to reduce the risk of AKI following $\mathrm{CPB}$ in cyanotic patients with congenital heart disease [35].

Collectively, these risk factors could be converted into a simple, accurate, and reliable bedside risk tool, which should promote improved clinician-patient discussions about risks of CPB-associated AKI. High-risk patients (defined as an age $>70$ years, female gender, smoking history, left ventricular ejection fraction $<35 \%$, worse borderline renal function, increased $\mathrm{sCr}$ levels around the perioperative period, decreased hemoglobin concentration, hemodilution, and genetic susceptibility) should be targeted for renal protective strategies, and clinicians should focus on preventing the occurrence of AKI following CPB in these patients (Figure 1 and Table 1). Taking these factors into account, improvements to $\mathrm{CPB}$ technologies have been proposed to limit the risk of occurrence of AKI. Long et al. have proposed that perfusion techniques may be associated with the incidence of AKI [8]. Furthermore, a set of interventions that are mainly aimed at limiting and improving these risk factors may be effective at reducing the AKI rate. These interventions include improving patient conditions, avoiding the use of contrast agents before $\mathrm{CPB}$, avoiding any decrease in the hemoglobin concentration, reasonably using hemodilution, improving oxygen delivery, and controlling the surgery time.

\section{Renal Replacement Therapy}

A meta-analysis of cohort studies reported that RRT is administered to $2.1 \%$ of patients with $\mathrm{CPB}$-associated $\mathrm{AKI}$ [7]. According to another study, 2.2\% of patients required long-term renal support [21]. The early institution of both peritoneal dialysis (PD) for AKI and low cardiac output after cardiac operations removes fluid, thus easing the fluid restriction and improving cardiopulmonary function [72]. In infants at high risk of developing AKI, PD catheter placement has also been shown to be safe, and it is associated with an earlier negative fluid balance, earlier extubation, improved inotrope scores, fewer electrolyte imbalances requiring correction, and improved clinical outcomes [73]. In general, dialysis-associated complications have not been observed during PD [24, 74]. When PD was contraindicated, the use of two small single-lumen catheters in separate veins enables consistent and effective hemodiafiltration in neonates and infants with challenging vascular access, allowing an excellent normalization of the blood flow of metabolic derangements and significant fluid removal [75].

In addition to PD, continuous RRT (CRRT) and hemodialysis (HD) are other suitable RRTs for the treatment of AKI [76]. CRRT is a safe and effective method for fluid and electrolyte homeostasis that allows hyperalimentation in infants and children after cardiac operations [77]. According to a multivariate analysis, intraoperative CRRT preserves postoperative renal function in patients with moderate renal dysfunction before surgery (OR, 0.8; 95\% CI, 0.71-0.99; $P=0.02$ ) [33]. However, the utilization of CRRT is limited by its high cost. As shown in the study by Sugahara and Suzuki [78], the early initiation of HD therapy (as soon as the urine output decreased to $<30 \mathrm{~mL} /$ hour) might increase the survival of patients with AKI following cardiac surgery, which was obviously superior to the late-HD group $(P<0.01)$. In addition, perioperative prophylactic $H D$ also decreases operative mortality and morbidity rates in high-risk patients [49]. Furthermore, modern CRRT and HD machines are equipped with exact volumetric systems that direct fluid removal and online solute clearance monitoring, providing obvious superiority and improving physician "comfort" compared with PD 


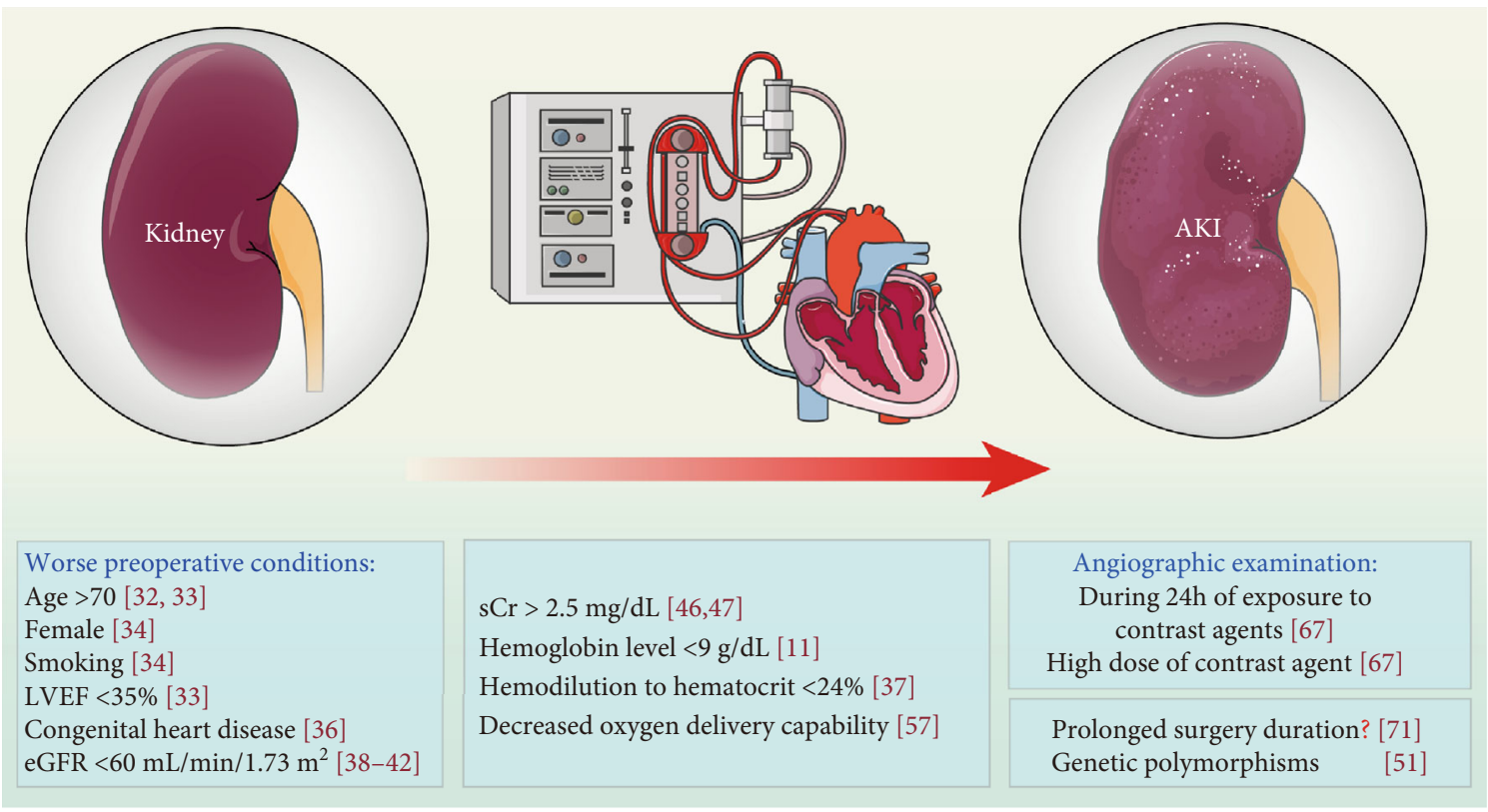

FIGURE 1: Risk factors for CPB-associated AKI. In addition to a set of independent risk factors that has been widely accepted and included in some predictive models, other risk factors are related to CPB-associated AKI, including genetic polymorphisms, a decreased hemoglobin concentration, hemodilution, and a decreased oxygen delivery capability. AKI: acute kidney injury; LVEF: left ventricular ejection fraction; eGFR: estimated glomerular filtration rate; sCr: serum creatinine.

TABLE 1: Risk factors for acute renal dysfunction following cardiopulmonary bypass.

\begin{tabular}{|c|c|c|}
\hline Factors & Significance & References \\
\hline Age $>70$ & An independent risk factor for AKI following $\mathrm{CPB}$ & {$[32,33]$} \\
\hline Female & An independent risk factor for AKI following CPB & [34] \\
\hline Smoking & An independent risk factor for AKI following $\mathrm{CPB}$ & {$[34]$} \\
\hline $\mathrm{LVEF}<35 \%$ & An independent risk factor for AKI following $\mathrm{CPB}$ & [33] \\
\hline Congenital heart disease & Children with congenital heart disease are at high risk of AKI happening & [36] \\
\hline $\mathrm{eGFR}<60 \mathrm{~mL} / \mathrm{min} / 1.73 \mathrm{~m}^{2}$ & An independent risk factor for AKI following $\mathrm{CPB}$ & {$[38-42]$} \\
\hline $\mathrm{sCr}>2.5 \mathrm{mg} / \mathrm{dL}$ & An independent risk factor for $\mathrm{AKI}$ following $\mathrm{CPB}$ & {$[46,47]$} \\
\hline Genetic polymorphisms & $\begin{array}{l}\text { Patients with the rs } 1617640 \text { TT risk allele are more likely to develop AKI following } \\
\text { CPB }\end{array}$ & {$[51]$} \\
\hline Hemoglobin level $<9$ g/dL & An independent risk factor for $\mathrm{AKI}$ following $\mathrm{CPB}$ & {$[11]$} \\
\hline Hemodilution to hematocrit $<24 \%$ & An independent risk factor for $\mathrm{AKI}$ following $\mathrm{CPB}$ & {$[37]$} \\
\hline Oxygen delivery & Increasing oxygen might be protective against $\mathrm{AKI}$ following $\mathrm{CPB}$ & {$[57]$} \\
\hline During $24 \mathrm{~h}$ of exposure to contrast agents & $\begin{array}{l}\text { Restricting angiographic examination on the day of operation reduced } \\
\text { the AKI rate }\end{array}$ & [67] \\
\hline High dose of contrast agent & An independent risk factor for AKI following $\mathrm{CPB}$ & [67] \\
\hline Prolonged surgery duration & $\begin{array}{l}\text { Prolonged time on } \mathrm{CPB} \text { might be associated with increased risk of developing AKI } \\
\text { following } \mathrm{CPB}\end{array}$ & [71] \\
\hline
\end{tabular}

LVEF: left ventricular ejection fraction; eGFR: estimated glomerular filtration rate; sCr: serum creatinine.

that contributes to potentially unpredictable fluid removal rates and possible inadequate solute clearances [76]. Notably, due to the hemodynamic instability of children, RRT has been improved to reduce the cost and enhance the therapeutic effects on neonatal populations (this issue has been discussed in another excellent review [79]).
The early institution of ultrafiltration in the operating room and RRT during the postoperative period may decrease the activity of the proinflammatory milieu and the resulting systemic effects [80]. The early initiation of RRT may prevent fluid overload and result in improved infant outcomes. Despite the theoretical advantages of using RRT and the 
effective control of uremia, the mortality associated with AKI following CPB remains high, and it is most likely determined by the number of failed organ systems [81]. Thus, the management of CPB-associated AKI should be aimed at relying on more comprehensive interventions.

\section{Other Interventions}

The early mortality of patients utilizing RRT is still very high (RR, 5.3; 95\% CI, 3.4-8.1) [7]. Combinations of more effective interventions with RRT are urgently needed to prevent and manage $\mathrm{CPB}$-associated AKI.

Statin therapy is reported to be effective at reducing the risk of contrast-induced AKI [82-84]. Several studies have focused on the effects of statins on CPB-associated AKI. Interestingly, in these studies, patients treated postoperatively with statins showed a significant reduction in $\mathrm{sCr}$ levels. However, some studies did not show an association between preoperative statin usage and a decreased incidence of AKI in adults who underwent surgery that required $\mathrm{CPB}$ $[6,85]$. A recent meta-analysis by Wang and colleagues [86] revealed that preoperative statin therapy reduced the incidence of postoperative AKI by $13 \%$ and $7 \%$ in subgroups of patients whose AKI was evaluated using the AKIN or the RIFLE criteria, respectively, without significant heterogeneity. Collectively, statins might be a promising therapy for reducing renal complications and the incidence of AKI in patients undergoing CPB surgery [87], and this topic warrants further investigation.

Postoperative AKI has been shown to be associated with the increased intraoperative release of hemeprotein $[88,89]$. Hemeprotein release following a mechanical injury is inevitable, but the association between increased plasma free hemoglobin (fHb) levels and renal injury provides new insights into the pathophysiology of AKI $[89,90]$.

\section{Further Perspectives}

The incidence and prognosis of $\mathrm{CPB}$-associated AKI are influenced by multiple factors. Hence, predictive risk models must be established to comprehensively assess the general condition of patients $[91,92]$. Several predictive risk models have been established, including the use of Mehta scores with the C statistic of 0.83 (10 variables: preoperative sCr level, age, race, type of surgery, diabetes, shock, New York Heart Association class, lung disease, recent myocardial infarction, and prior cardiovascular surgery are included in this bedside tool that is aimed at evaluating the need for postoperative dialysis) [93], Cleveland Clinic scores with an overall area under the receiver operating characteristic (ROC) curve of 0.81 (10 variables have been validated for a maximum score of 17: female gender, congestive heart failure, LVEF, preoperative use of intra-aortic balloon pump, COPD, diabetes, previous cardiac surgery, emergency surgery, type of surgery, and preoperative creatinine level) [94], and Simplified Renal Index scores with an overall area under the ROC curve of 0.81 ( 7 variables are identified for a maximum score of 8 : GFR, diabetes, ejection fraction, previous cardiac surgery, procedure other than coronary artery bypass grafting, intra- aortic balloon pump, and nonelective case) [95]. Among these three models, the Cleveland scoring system offers the best discriminative value for predicting postoperative RRT and covers most patients undergoing CPB surgery [96]. It can also be used to predict the composite end point for severe AKI, which enables its broader application in patients at risk of postoperative AKI. Some other predictive scoring systems exist for postoperative RRT [97-99], but these scales have limitations in assessing CPB-associated AKI. Some other models have also been established to estimate CPBassociated AKI but are limited by their use of small derivation cohorts $[100,101]$. The addition of novel biomarkers, particularly when used in combinations, significantly increased the predictive value of the model in another study [10]. The ability to accurately assess the risk of developing CPBassociated AKI before surgery should improve clinical management, lead to the earlier involvement of specialist services, and allow more informed decision making; however, further studies are needed to develop a more comprehensive and accurate assessment system.

While the sCr level, which is accepted as a delayed marker of AKI, remains within normal limits [102], other biomarkers are able to identify tubular and glomerular damage. The urine and serum biomarkers for CPB-associated AKI have been separately summarized in Tables 2 and 3. Combinations of two or more of these biomarkers may provide increased diagnostic sensitivity and specificity for evaluating AKI following $\mathrm{CPB}$. Urine neutrophil gelatinase-associated lipocalin (NGAL), interleukin-18 (IL-18), liver fatty acid-binding protein (L-FABP), and kidney injury molecule- (KIM-) 1 levels are sequential predictive biomarkers of AKI that correlate with disease severity and clinical outcomes in pediatric patients who undergo CPB $[103,104]$. These biomarkers, particularly when used in combination, may help to establish the timing of injury and allow earlier intervention for AKI [10, 105]. The currently available studies included only limited urinary biomarkers without including other promising biomarkers, such as cystatin $\mathrm{C}$, asymmetric dimethylarginine (ADMA), and NGAL [106]. Thus, a comprehensive "panel" of promising biomarkers that can be used individually and in combination should be developed to optimize both the sensitivity and specificity of predicting and diagnosing CPB-associated AKI. Parikh et al. [107] also proposed that a combination including NGAL and IL-18 might be used for the reliable early diagnosis and prognosis of AKI at all time points after CPB and substantially before an increase in sCr levels is considered to be diagnostic. Some novel predictors, such as elevated levels of plasma renin and IL-8, were recently shown to be associated with development of CPB-associated AKI [108-110], whereas elevated concentration of the serum macrophage migration inhibitory factor is associated with decreased risk of CPBassociated AKI [111]. These factors could be further included in these predictive models. Collectively, a more comprehensive examination of the relevant novel biomarkers both individually and in combination is urgently needed.

Novel biomarkers indicate that free iron-mediated toxicity is an important mechanism of AKI in patients receiving cardiac surgery with CPB [112]. Haase et al. [113] analyzed the pathophysiological implications of some novel renal 
TABLE 2: Summary of urine biomarkers for CPB-associated AKI.

\begin{tabular}{|c|c|c|}
\hline Novel biomarkers & Significance & Reference \\
\hline Urine NGAL & Predictive time point of NGAL for CPB-associated AKI can be advanced as early as $2 \mathrm{~h}$ postoperatively. & $\begin{array}{c}{[10,107,} \\
122]\end{array}$ \\
\hline Urine IL-18 & $\begin{array}{l}\text { Urine IL-18 increased at } 4-6 \mathrm{~h} \text { after CPB, peaked at over } 25 \text {-folds at } 12 \mathrm{~h} \text {, and remained markedly } \\
\text { elevated up to } 48 \mathrm{~h} \text { in AKI patients after CPB. }\end{array}$ & [107] \\
\hline Urine AIM & Urinary AIM peaks within 2 hours in children who developed AKI after CPB surgery. & {$[102]$} \\
\hline Urine AAG & Urinary AAG peaks within 2 hours in children who developed AKI after CPB surgery. & {$[102]$} \\
\hline Urine Alb & Urinary Alb peaks within 2 hours in children who developed AKI after CPB surgery. & [102] \\
\hline Urine NAG & $\begin{array}{c}\text { During surgery urinary excretion of NAG increased in patients with AKI, reaching peak levels at } 15 \text { min } \\
\text { after reperfusion. }\end{array}$ & [89] \\
\hline Urine hepcidin-25 & $\begin{array}{l}\text { Elevated urinary hepcidin-25 at } 24 \mathrm{~h} \text { is a strong predictor of avoidance of AKI beyond } \\
\text { postoperative day } 1 .\end{array}$ & [123] \\
\hline $\begin{array}{l}\text { Urine TIMP-2 } \\
\text { Urine IGFBP7 }\end{array}$ & Urine TIMP-2 and IGFBP7 are significantly higher in patients with AKI 1 hour after CPB start. & {$[124]$} \\
\hline $\begin{array}{l}\text { Urine vasopressinase } \\
\text { activity }\end{array}$ & $\begin{array}{l}\text { For patients undergoing } \mathrm{CPB} \text { surgery, their urine vasopressinase activity peaks at the time of arrival to } \\
\text { the ICU. In patients who were diagnosed with AKI, urine vasopressinase activity peaked } 30 \text { minutes into } \\
\text { CPB. }\end{array}$ & [125] \\
\hline
\end{tabular}

NGAL: neutrophil gelatinase-associated lipocalin; IL-18: interleukin-18; AIM: $\alpha$ (1)-microglobulin; AAG: $\alpha$ (1)-acid glycoprotein; Alb: albumin; NAG: N-acetylbeta-D-glucosaminidase.

TABLE 3: Summary of serum biomarkers for CPB-associated AKI.

\begin{tabular}{|c|c|c|}
\hline Novel biomarkers & Significance & Reference \\
\hline Serum cystatin C & $\begin{array}{l}\text { The } 12 \mathrm{~h} \text { cystatin } \mathrm{C} \text { strongly correlated with severity and duration of AKI as well as length of hospital } \\
\text { stay. In multivariable analysis, } 12 \mathrm{~h} \text { cystatin } \mathrm{C} \text { remained a powerful independent predictor of AKI. The } \\
\text { discriminatory capacity of plasma cystatin C measured preoperatively and } 2 \text { hours after the conclusion of } \\
\text { CPB was modest. }\end{array}$ & [126] \\
\hline Serum ADMA & $\begin{array}{l}\text { Patients with elevated ADMA before surgery were more likely to have prolonged mechanical ventilation, } \\
\text { develop LCOS, require an extended length of stay, and require reoperation. ADMA levels inversely } \\
\text { correlated with eGFR, but did not predict AKI. Preoperative serum ADMA appears to identify pediatric } \\
\text { cardiac surgery patients at risk of poor postoperative outcomes following CPB. }\end{array}$ & [127] \\
\hline Plasma fHb & During surgery, plasma fHb increased in patients with AKI, reaching peak levels at $2 \mathrm{~h}$ after reperfusion. & [89] \\
\hline $\begin{array}{l}\text { Serum vasopressinase } \\
\text { activity }\end{array}$ & $\begin{array}{l}\text { For patients undergoing } \mathrm{CPB} \text { surgery, their serum vasopressinase activity peaks at the time of arrival to } \\
\text { the ICU. In patients who were diagnosed with AKI, serum vasopressinase activity peaked } 30 \text { minutes } \\
\text { into CPB. }\end{array}$ & [125] \\
\hline $\begin{array}{l}\text { Plasma micro-RNAs } \\
\text { and microvesicle }\end{array}$ & $\begin{array}{l}\text { A number of micro-RNAs (miR-192-5p, miR-487a-3p, miR-490-3p, and miR-501-3p) and microvesicles } \\
\text { were differentially expressed in AKI children at } 6-12 \mathrm{~h} \text { following CPB, which might serve as tools for } \\
\text { stratification of children at risk of AKI. }\end{array}$ & [128] \\
\hline Serum miR-494 & $\begin{array}{l}\text { Serum level of miR-494 in the death group due to AKI was more than fourfold higher than that in the } \\
\text { survival group. Furthermore, its level was identified as an independent risk factor for death due to CPB- } \\
\text { associated AKI. }\end{array}$ & [129] \\
\hline Serum NGAL & $\begin{array}{l}\text { The serum levels of NGAL in the death group were significantly higher than those in the survival group. } \\
\text { Furthermore, the expression level of serum NGAL was positively correlated with that of miR-494 in the } \\
\text { death group. }\end{array}$ & [129] \\
\hline Serum KIM-1 & $\begin{array}{l}\text { The serum levels of KIM- } 1 \text { in the death group were significantly higher than those in the survival group. } \\
\text { The expression level of serum KIM-1 was positively correlated with that of miR- } 494 \text { in the death group. }\end{array}$ & [129] \\
\hline
\end{tabular}

biomarkers in relation to $\mathrm{CPB}$-associated $\mathrm{AKI}$ and found that NGAL, L-FABP, and alpha-1 microglobulin predict the development of CPB-associated AKI, while hepcidin isoforms appeared to predict protection from AKI [114]. However, all of these biomarkers are involved in iron metabolism. A free iron-related, reactive oxygen species-mediated type of kidney injury appears to be the unifying pathophysiological connection between these biomarkers. The effects of deferoxamine, 


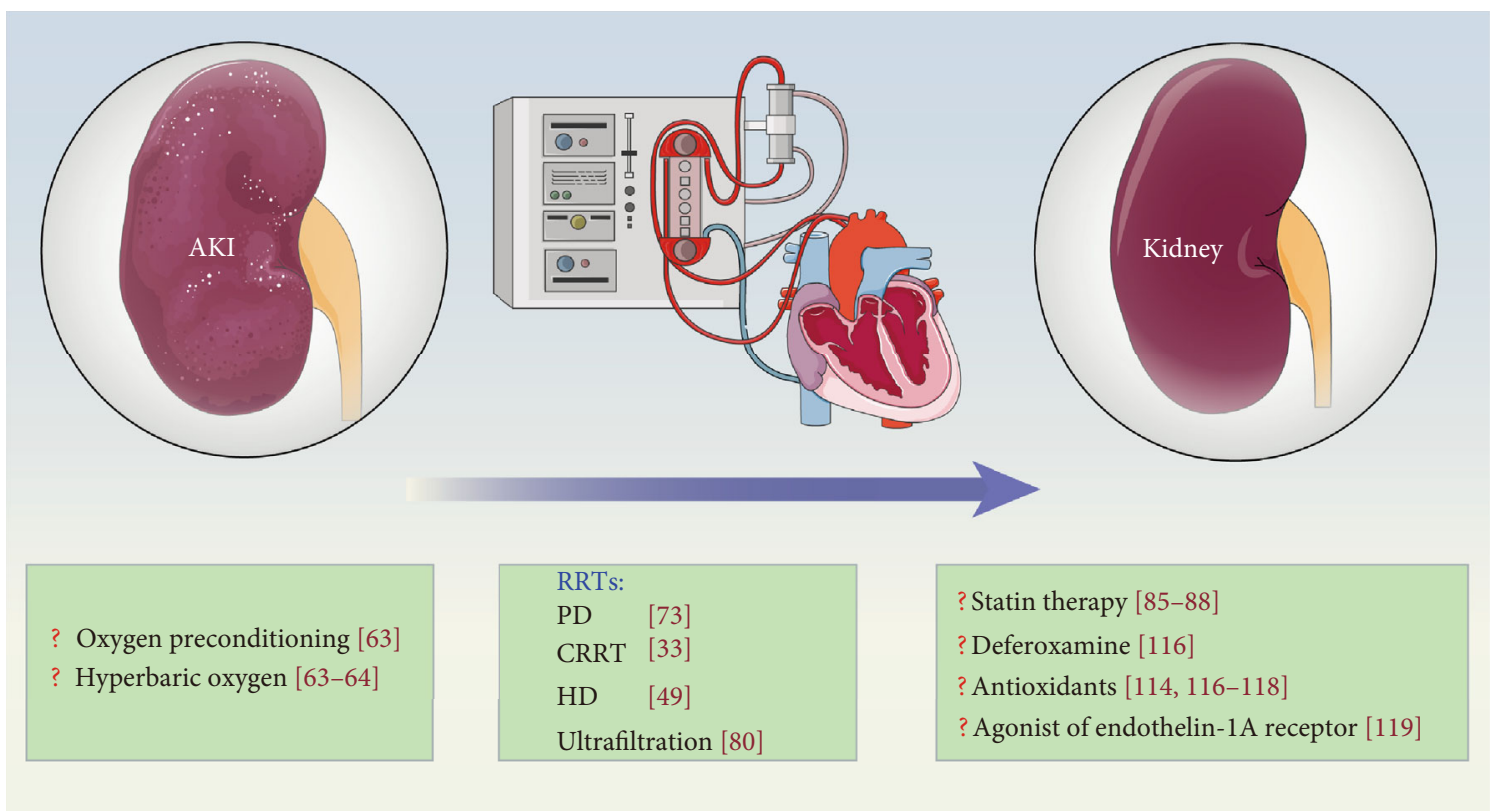

Figure 2: Potential interventions for CPB-associated AKI. RRT is efficient at managing CPB-associated AKI, and other potential interventions may further benefit patients undergoing CPB surgery. AKI: acute kidney injury; RRT: renal replacement therapy; PD: peritoneal dialysis; CRRT: continuous renal replacement therapy; HD: hemodialysis.

a sequestering agent used to complex iron ions, when used in combination with $\mathrm{N}$-acetylcysteine was inferior to the use of $\mathrm{N}$-acetylcysteine alone in treating gentamicin-induced AKI in adult male Wistar rats [115]. Further studies are needed to determine whether deferoxamine improves the control of AKI following CPB. Billings et al. [88] reported an association between postoperative AKI and both increased intraoperative hemeprotein release and increased lipid peroxidation, indicating a potential role for hemeprotein-induced oxidative damage in the pathogenesis of postoperative AKI. The role of excessive oxidative stress-induced AKI has been widely recognized, and it has been ameliorated by the application of antioxidants [113, 115-117]. Thus, approaches aimed at inhibiting excessive oxidative stress may be an attractive strategy for preventing CPB-associated AKI. CPB-associated AKI is associated with endothelial dysfunction, regional tissue hypoxia, and proximal tubular epithelial cell stress [118]. Antagonism of the endothelin-1A receptor reversed these changes and may therefore represent a therapeutic target for strategies aimed at preventing AKI after CPB surgery (Figure 2).

In a retrospective study, after adjusting for covariates and propensity scores, a multivariate analysis showed that offpump surgery preserved postoperative renal function in patients with moderate renal dysfunction before surgery (OR, 0.9; 95\% CI, 0.87-0.99; $P=0.04$ ) [33]. A difference between off-pump and on-pump coronary artery bypass graft surgery was identified in a randomized clinical trial [119]. The off-pump surgery reduced the risk of postoperative AKI by $17 \%$, but the authors did not provide evidence for improved preservation of renal functions at 1 year. Other studies have also supported the hypothesis that off-pump coronary artery bypass graft surgery reduces the risk of postoperative AKI
$[120,121]$. Based on these studies, interventions are required to reduce the risk of mild to moderate AKI following CPB without altering longer-term renal functions.

\section{Conclusions}

CPB-associated AKI remains a challenging problem with numerous risk factors, including age ( $>70$ years), female gender, smoking history, left ventricular ejection fraction of $<35 \%$, borderline renal function, increased sCr levels around the perioperative period, decreased hemoglobin concentrations, hemodilution, and genetic susceptibility (Figure 1 and Table 1). Improvements in our understanding of these factors and establishing models predicting mortality would be beneficial for strategies aimed at predicting and preventing CPBassociated AKI. Some novel biomarkers that may be used to predict and diagnose AKI have attracted attention, and combinations of these biomarkers, including urine (Table 2) and serum biomarkers (Table 3), may provide additional value. The development of a comprehensive "panel" of these risk factors and biomarkers would be useful. The importance and beneficial effect of using RRT for AKI after CPB was validated. Other interventions are needed to assist and increase the effects of RRT (Figure 2). The role of statins in preventing $\mathrm{AKI}$ in patients undergoing CPB surgery shows promise and should be further investigated. Furthermore, several studies have investigated the possible mechanisms underlying CPBassociated $\mathrm{AKI}$ and found that $\mathrm{fHb}$, free iron, excess oxidative stress, and endothelial dysfunction may be new therapeutic targets for reducing the incidence of AKI and improving the clinical outcomes of patients after CPB surgery. 


\section{Data Availability}

None.

\section{Conflicts of Interest}

The authors declare that they have no conflicts of interest.

\section{Authors' Contributions}

Dianxiao Liu, Baohui Liu and Zhenxing Liang contributed equally to this work.

\section{Acknowledgments}

This study was supported by grants from the National Natural Science Foundation of China (81700236).

\section{References}

[1] J. H. Gibbon, "Application of a mechanical heart and lung apparatus to cardiac surgery," Minnesota Medicine, vol. 37, no. 3, pp. 171-185, 1954.

[2] J. Kirklin, J. Dushane, R. Patrick et al., "Intracardiac surgery with the aid of a mechanical pump-oxygenator system (gibbon type): report of eight cases," Proceedings of the Staff Meetings. Mayo Clinic, vol. 30, no. 10, pp. 201-206, 1955.

[3] E. J. Benjamin, M. J. Blaha, S. E. Chiuve et al., "Heart disease and stroke statistics-2017 update: a report from the American Heart Association," Circulation, vol. 135, no. 10, pp. e146e603, 2017.

[4] L. Vercaemst, "Hemolysis in cardiac surgery patients undergoing cardiopulmonary bypass: a review in search of a treatment algorithm," The Journal of Extra-Corporeal Technology, vol. 40, no. 4, pp. 257-267, 2008.

[5] S. Zhang, S. Wang, Q. Li et al., "Capillary leak syndrome in children with C4A-deficiency undergoing cardiac surgery with cardiopulmonary bypass: a double-blind, randomised controlled study," Lancet, vol. 366, no. 9485, pp. 556-562, 2005.

[6] M. Lewicki, I. Ng, and A. G. Schneider, "HMG CoA reductase inhibitors (statins) for preventing acute kidney injury after surgical procedures requiring cardiac bypass," Cochrane Database of Systematic Reviews, vol. 3, no. 11, article CD010480, 2015.

[7] J. W. Pickering, M. T. James, and S. C. Palmer, "Acute Kidney Injury and Prognosis After Cardiopulmonary Bypass: A Meta- analysis of Cohort Studies," American Journal of Kidney Diseases, vol. 65, no. 2, pp. 283-293, 2015.

[8] D. M. Long, E. Jenkins, and K. Griffith, "Perfusionist techniques of reducing acute kidney injury following cardiopulmonary bypass: an evidence-based review," Perfusion, vol. 30 , no. 1, pp. 25-32, 2015.

[9] M. H. Rosner and M. D. Okusa, "Acute kidney injury associated with cardiac surgery," Clinical Journal of the American Society of Nephrology, vol. 1, no. 1, pp. 19-32, 2005.

[10] C. D. Krawczeski, S. L. Goldstein, J. G. Woo et al., “Temporal relationship and predictive value of urinary acute kidney injury biomarkers after pediatric cardiopulmonary bypass," Journal of the American College of Cardiology, vol. 58, no. 22 , pp. 2301-2309, 2011
[11] M. Haase, R. Bellomo, D. Story et al., "Effect of mean arterial pressure, haemoglobin and blood transfusion during cardiopulmonary bypass on post-operative acute kidney injury," Nephrology, Dialysis, Transplantation, vol. 27, no. 1, pp. 153-160, 2012.

[12] R. Zakeri, N. Freemantle, V. Barnett et al., "Relation between mild renal dysfunction and outcomes after coronary artery bypass grafting," Circulation, vol. 112, 9 Suppl, pp. I2701275, 2005.

[13] C. E. Hobson, S. Yavas, M. S. Segal et al., "Acute kidney injury is associated with increased long-term mortality after cardiothoracic surgery," Circulation, vol. 119, no. 18, pp. $2444-$ 2453, 2009.

[14] I. Bahar, A. Akgul, M. A. Ozatik et al., "Acute renal failure following open heart surgery: risk factors and prognosis," Perfusion, vol. 20, no. 6, pp. 317-322, 2005.

[15] O. V. Hein, J. Birnbaum, K. D. Wernecke, W. Konertz, U. Jain, and C. Spies, "Three-year survival after four major post-cardiac operative complications," Critical Care Medicine, vol. 34, no. 11, pp. 2729-2737, 2006.

[16] R. L. Mehta, J. A. Kellum, S. V. Shah et al., "Acute Kidney Injury Network: report of an initiative to improve outcomes in acute kidney injury," Critical Care, vol. 11, no. 2, p. R31, 2007.

[17] R. Bellomo, C. Ronco, J. A. Kellum, R. L. Mehta, P. Palevsky, and Acute Dialysis Quality Initiative workgroup, “Acute renal failure - definition, outcome measures, animal models, fluid therapy and information technology needs: the second international consensus conference of the Acute Dialysis Quality Initiative (ADQI) group," Critical Care, vol. 8, no. 4, pp. R204-R212, 2004.

[18] S. G. Coca, B. Yusuf, M. G. Shlipak, A. X. Garg, and C. R. Parikh, "Long-term risk of mortality and other adverse outcomes after acute kidney injury: a systematic review and meta-analysis," American Journal of Kidney Diseases, vol. 53, no. 6, pp. 961-973, 2009.

[19] A. Bihorac, S. Yavas, S. Subbiah et al., "Long-term risk of mortality and acute kidney injury during hospitalization after major surgery," Annals of Surgery, vol. 249, no. 5, pp. 851858, 2009.

[20] A. Haase-Fielitz, M. Haase, R. Bellomo, and D. Dragun, "Genetic polymorphisms in sepsis- and cardiopulmonary bypass-associated acute kidney injury," Contributions to Nephrology, vol. 156, pp. 75-91, 2007.

[21] H. Luckraz, M. B. Gravenor, R. George et al., "Long and short-term outcomes in patients requiring continuous renal replacement therapy post cardiopulmonary bypass," European Journal of Cardio-Thoracic Surgery, vol. 27, no. 5, pp. 906-909, 2005.

[22] M. D. Kertai, S. Zhou, J. A. Karhausen et al., "Platelet counts, acute kidney injury, and mortality after coronary artery bypass grafting surgery," Anesthesiology, vol. 124, no. 2, pp. 339-352, 2016.

[23] J. A. Kellum, N. Lameire, and for the KDIGO AKI Guideline Work Group, "Diagnosis, evaluation, and management of acute kidney injury: a KDIGO summary (Part 1)," Critical Care, vol. 17, no. 1, p. 204, 2013.

[24] J. E. Kist-van Holthe tot Echten, C. A. Goedvolk, M. B. Doornaar et al., "Acute renal insufficiency and renal replacement therapy after pediatric cardiopulmonary bypass surgery," Pediatric Cardiology, vol. 22, no. 4, pp. 321-326, 2001. 
[25] R. Goldberg and P. Dennen, "Long-term outcomes of acute kidney injury," Advances in Chronic Kidney Disease, vol. 15, no. 3, pp. 297-307, 2008.

[26] E. Baskin, K. S. Gulleroglu, A. Saygili, S. Aslamaci, B. Varan, and K. Tokel, "Peritoneal dialysis requirements following open-heart surgery in children with congenital heart disease," Renal Failure, vol. 32, no. 7, pp. 784-787, 2010.

[27] M. Meersch, C. Schmidt, A. Hoffmeier et al., "Prevention of cardiac surgery-associated AKI by implementing the KDIGO guidelines in high risk patients identified by biomarkers: the PrevAKI randomized controlled trial," Intensive Care Medicine, vol. 43, no. 11, pp. 1551-1561, 2017.

[28] M. Ranucci, T. Aloisio, G. Carboni et al., "Acute kidney injury and hemodilution during cardiopulmonary bypass: a changing scenario," The Annals of Thoracic Surgery, vol. 100, no. 1, pp. 95-100, 2015.

[29] M. E. Ostermann, D. Taube, C. J. Morgan, and T. W. Evans, "Acute renal failure following cardiopulmonary bypass: a changing picture," Intensive Care Medicine, vol. 26, no. 5, pp. 565-571, 2000.

[30] M. H. Rosner, “Acute kidney injury in the elderly," Clinics in Geriatric Medicine, vol. 29, no. 3, pp. 565-578, 2013.

[31] D. Helgason, S. Helgadottir, A. Ahlsson et al., "Acute kidney injury after acute repair of type a aortic dissection," The Annals of Thoracic Surgery, vol. S0003-4975, no. 20, pp. 31505-31508, 2020.

[32] R. R. Ge Ng, S. T. Huey Chew, W. Liu, and L. Kah Ti, "Persistent kidney injury at hospital discharge after cardiac surgery with cardiopulmonary bypass in patients with normal preoperative serum creatinine and normal estimated glomerular filtration rate," Journal of Cardiothoracic and Vascular Anesthesia, vol. 28, no. 6, pp. 1453-1458, 2014.

[33] A. Roscitano, U. Benedetto, M. Goracci, F. Capuano, R. Lucani, and R. Sinatra, "Intraoperative continuous venovenous hemofiltration during coronary surgery," Asian Cardiovascular \& Thoracic Annals, vol. 17, no. 5, pp. 462-466, 2009.

[34] J. Neugarten, S. Sandilya, B. Singh, and L. Golestaneh, "Sex and the risk of AKI following cardio-thoracic surgery: a meta-analysis," Clinical Journal of the American Society of Nephrology, vol. 11, no. 12, pp. 2113-2122, 2016.

[35] S. Dittrich, K. Kurschat, I. Dähnert et al., "Renal function after cardiopulmonary bypass surgery in cyanotic congenital heart disease," International Journal of Cardiology, vol. 73, no. 2, pp. 173-179, 2000.

[36] Y. Toda and K. Sugimoto, "AKI after pediatric cardiac surgery for congenital heart diseases-recent developments in diagnostic criteria and early diagnosis by biomarkers," Journal of Intensive Care, vol. 5, no. 1, p. 49, 2017.

[37] R. H. Habib, A. Zacharias, T. A. Schwann et al., "Role of hemodilutional anemia and transfusion during cardiopulmonary bypass in renal injury after coronary revascularization: implications on operative outcome," Critical Care Medicine, vol. 33 , no. 8, pp. 1749-1756, 2005.

[38] C. Ortega-Loubon, M. Fernandez-Molina, Y. CarrascalHinojal, and E. Fulquet-Carreras, "Cardiac surgeryassociated acute kidney injury," Annals of Cardiac Anaesthesia, vol. 19, no. 4, pp. 687-698, 2016.

[39] H. Y. Fu, N. K. Chou, Y. S. Chen, and H. Y. Yu, "Risk factor for acute kidney injury in patients with chronic kidney disease receiving valve surgery with cardiopulmonary bypass," Asian Journal of Surgery, vol. 44, no. 1, pp. 229-234, 2021.
[40] C. Ortega-Loubon, M. Fernandez-Molina, L. Paneda-Delgado, P. Jorge-Monjas, and Y. Carrascal, "Predictors of postoperative acute kidney injury after coronary artery bypass graft surgery," Brazilian Journal of Cardiovascular Surgery, vol. 33, no. 4, pp. 323-329, 2018.

[41] Z. Yue, G. Yan-Meng, and L. Ji-Zhuang, "Prediction model for acute kidney injury after coronary artery bypass grafting: a retrospective study," International Urology and Nephrology, vol. 51, no. 9, pp. 1605-1611, 2019.

[42] H. M. Reazaul Karim, M. Yunus, and S. Dey, "A retrospective comparison of preoperative estimated glomerular filtration rate as a predictor of postoperative cardiac surgery associated acute kidney injury," Annals of Cardiac Anaesthesia, vol. 23, no. 1, pp. 53-58, 2020.

[43] M. Ono, G. J. Arnaoutakis, D. M. Fine et al., "Blood pressure excursions below the cerebral autoregulation threshold during cardiac surgery are associated with acute kidney injury," Critical Care Medicine, vol. 41, no. 2, pp. 464-471, 2013.

[44] Y. Han, G. Zhu, L. Han et al., "Short-term rosuvastatin therapy for prevention of contrast-induced acute kidney injury in patients with diabetes and chronic kidney disease," Journal of the American College of Cardiology, vol. 63, no. 1, pp. 62-70, 2014.

[45] M. Moschopoulou, F. C. Ampatzidou, C. Loutradis et al., "Diabetes mellitus does not affect the incidence of acute kidney injury after cardiac surgery; a nested case-control study," Journal of Nephrology, vol. 29, no. 6, pp. 835-845, 2016.

[46] N. Huggins, A. Nugent, V. Modem et al., "Incidence of acute kidney injury following cardiac catheterization prior to cardiopulmonary bypass in children," Catheterization and Cardiovascular Interventions, vol. 84, no. 4, pp. 615-619, 2014.

[47] the TACS Investigators, K. Karkouti, V. Rao, C. T. Chan, and D. N. Wijeysundera, "Early rise in postoperative creatinine for identification of acute kidney injury after cardiac surgery," Canadian Journal of Anesthesia, vol. 64, no. 8, pp. 801-809, 2017.

[48] A. B. Kumar, M. Suneja, and B. Riou, "Cardiopulmonary bypass-associated acute kidney injury," Anesthesiology, vol. 114, no. 4, pp. 964-970, 2011.

[49] I. Durmaz, T. Yagdi, T. Calkavur et al., "Prophylactic dialysis in patients with renal dysfunction undergoing on-pump coronary artery bypass surgery," The Annals of Thoracic Surgery, vol. 75, no. 3, pp. 859-864, 2003.

[50] D. E. Leaf, S. C. Body, J. D. Muehlschlegel et al., "Length polymorphisms in heme oxygenase-1 and AKI after cardiac surgery," Journal of the American Society of Nephrology, vol. 27, no. 11, pp. 3291-3297, 2016.

[51] A. F. Popov, E. G. Schulz, J. D. Schmitto et al., "Relation between renal dysfunction requiring renal replacement therapy and promoter polymorphism of the erythropoietin gene in cardiac surgery," Artificial Organs, vol. 34, no. 11, pp. 961-968, 2010.

[52] M. Stafford-Smith, Y. J. Li, J. P. Mathew et al., "Genome-wide association study of acute kidney injury after coronary bypass graft surgery identifies susceptibility loci," Kidney International, vol. 88, no. 4, pp. 823-832, 2015.

[53] B. Perek, D. Maison, S. Budnick et al., "Preoperative blood morphology and incidence of acute kidney injury after onpump coronary artery bypass grafting - a single-center preliminary report," Polish Journal of Cardio-Thoracic Surgery, vol. 15, no. 1, pp. 18-22, 2018. 
[54] S. Soh, J. K. Shim, J. W. Song, B. Kang, and Y. L. Kwak, "Perioperative nadir hemoglobin concentration and outcome in off-pump coronary artery bypass surgery- a retrospective review," Circulation Journal, vol. 85, no. 1, pp. 37-43, 2020.

[55] J. P. Wanderer and J. P. Rathmell, "Cardiopulmonary bypass, renal oxygenation, \& acute kidney injury," Anesthesiology, vol. 126, no. 2, p. A21, 2017.

[56] S. Svenmarker, S. Haggmark, A. Holmgren, and U. Naslund, "Serum markers are not reliable measures of renal function in conjunction with cardiopulmonary bypass," Interactive Cardiovascular and Thoracic Surgery, vol. 12, no. 5, pp. 713$717,2011$.

[57] L. Lannemyr, G. Bragadottir, V. Krumbholz, B. Redfors, J. Sellgren, and S. E. Ricksten, "Effects of cardiopulmonary bypass on renal perfusion, filtration, and oxygenation in patients undergoing cardiac surgery," Anesthesiology, vol. 126, no. 2, pp. 205-213, 2017.

[58] M. Ranucci, F. Romitti, G. Isgrò et al., "Oxygen delivery during cardiopulmonary bypass and acute renal failure after coronary operations," The Annals of Thoracic Surgery, vol. 80, no. 6, pp. 2213-2220, 2005.

[59] M. Ranucci, "Perioperative renal failure: hypoperfusion during cardiopulmonary bypass?," Seminars in Cardiothoracic and Vascular Anesthesia, vol. 11, no. 4, pp. 265-268, 2007.

[60] D. S. Prough and R. Esenaliev, "Monitoring the brain to save the kidneys," Critical Care Medicine, vol. 41, no. 2, pp. 671672, 2013.

[61] R. S. Kramer, C. R. Herron, R. C. Groom, and J. R. Brown, "Acute kidney injury subsequent to cardiac surgery," The Journal of Extra-Corporeal Technology, vol. 47, no. 1, pp. 16-28, 2015.

[62] M. J. Bennett, C. Rajakaruna, S. Bazerbashi, G. Webb, M. Gomez-Cano, and C. Lloyd, "Oxygen delivery during cardiopulmonary bypass (and renal outcome) using two systems of extracorporeal circulation: a retrospective review," Interactive Cardiovascular and Thoracic Surgery, vol. 16, no. 6, pp. 760-764, 2013.

[63] H. Sekiguchi, Y. Ajiro, Y. Uchida et al., "Oxygen preconditioning prevents contrast-induced nephropathy (OPtion CIN study)," Journal of the American College of Cardiology, vol. 62, no. 2, pp. 162-163, 2013.

[64] S. Ayvaz, B. Aksu, M. Kanter et al., "Preventive effects of hyperbaric oxygen treatment on glycerol-induced myoglobinuric acute renal failure in rats," Journal of Molecular Histology, vol. 43, no. 2, pp. 161-170, 2012.

[65] E. Solmazgul, G. Uzun, H. Cermik, E. M. Atasoyu, S. Aydinoz, and S. Yildiz, "Hyperbaric oxygen therapy attenuates renal ischemia/reperfusion injury in rats," Urologia Internationalis, vol. 78, no. 1, pp. 82-85, 2007.

[66] S. Aydinoz, G. Uzun, H. Cermik et al., "Effects of different doses of hyperbaric oxygen on cisplatin-induced nephrotoxicity," Renal Failure, vol. 29, no. 3, pp. 257-263, 2007.

[67] M. Ranucci, A. Ballotta, A. Kunkl et al., "Influence of the timing of cardiac catheterization and the amount of contrast media on acute renal failure after cardiac surgery," The American Journal of Cardiology, vol. 101, no. 8, pp. 1112-1118, 2008.

[68] T. Wittlinger, M. Maus, I. Kutschka, H. Baraki, and M. G. Friedrich, "Risk assessment of acute kidney injury following cardiopulmonary bypass," Journal of Cardiothoracic Surgery, vol. 16, no. 1, p. 4, 2021.
[69] Y. Y. Jiang, X. R. Kong, F. L. Xue et al., "Incidence, risk factors and clinical outcomes of acute kidney injury after heart transplantation: a retrospective single center study," Journal of Cardiothoracic Surgery, vol. 15, no. 1, p. 302, 2020.

[70] X. Ma, J. Li, Y. Yun et al., "Risk factors analysis of acute kidney injury following open thoracic aortic surgery in the patients with or without acute aortic syndrome: a retrospective study," Journal of Cardiothoracic Surgery, vol. 15, no. 1, p. 213, 2020.

[71] E. Mancini, F. Caramelli, M. Ranucci et al., "Is time on cardiopulmonary bypass during cardiac surgery associated with acute kidney injury requiring dialysis?," Hemodialysis International, vol. 16, no. 2, pp. 252-258, 2012.

[72] H. A. Werner, D. F. Wensley, D. S. Lirenman, and J. G. LeBlanc, "Peritoneal dialysis in children after cardiopulmonary bypass," The Journal of Thoracic and Cardiovascular Surgery, vol. 113, no. 1, pp. 64-70, 1997.

[73] D. M. Kwiatkowski, S. Menon, C. D. Krawczeski et al., "Improved outcomes with peritoneal dialysis catheter placement after cardiopulmonary bypass in infants," The Journal of Thoracic and Cardiovascular Surgery, vol. 149, no. 1, pp. 230-236, 2015.

[74] K. Book, G. Ohqvist, V. O. Bjork, S. Lundberg, and G. Settergren, "Peritoneal dialysis in infants and children after open heart surgery," Scandinavian Journal of Thoracic and Cardiovascular Surgery, vol. 16, no. 3, pp. 229-233, 2009.

[75] K. El Masri, K. Jackson, S. Borasino, M. Law, D. Askenazi, and J. Alten, "Successful continuous renal replacement therapy using two single-lumen catheters in neonates and infants with cardiac disease," Pediatric Nephrology, vol. 28, no. 12, pp. 2383-2387, 2013.

[76] B. Cullis, M. Abdelraheem, G. Abrahams et al., "Peritoneal dialysis for acute kidney injury," Peritoneal Dialysis International, vol. 34, no. 5, pp. 494-517, 2014.

[77] G. Paret, A. J. Cohen, D. J. Bohn et al., "Continuous arteriovenous hemofiltration after cardiac operations in infants and children," The Journal of Thoracic and Cardiovascular Surgery, vol. 104, no. 5, pp. 1225-1230, 1992.

[78] S. Sugahara and H. Suzuki, "Early start on continuous hemodialysis therapy improves survival rate in patients with acute renal failure following coronary bypass surgery," Hemodialysis International, vol. 8, no. 4, pp. 320-325, 2004.

[79] R. Sinha, S. K. Sethi, T. Bunchman, V. Lobo, and R. Raina, "Prolonged intermittent renal replacement therapy in children," Pediatric Nephrology, vol. 33, no. 8, pp. 1283-1296, 2018.

[80] S. Picca, Z. Ricci, and S. Picardo, "Acute kidney injury in an infant after cardiopulmonary bypass," Seminars in Nephrology, vol. 28, no. 5, pp. 470-476, 2008.

[81] S. V. Baudouin, J. Wiggins, B. F. Keogh, C. J. Morgan, and T. W. Evans, "Continuous veno-venous haemofiltration following cardio-pulmonary bypass. Indications and outcome in 35 patients," Intensive Care Medicine, vol. 19, no. 5, pp. 290-293, 1993.

[82] A. Ukaigwe, P. Karmacharya, M. Mahmood et al., "MetaAnalysis on Efficacy of _Statins_ for Prevention of Contrast-Induced Acute Kidney Injury in Patients Undergoing Coronary Angiography," The American Journal of Cardiology, vol. 114, no. 9, pp. 1295-1302, 2014.

[83] J. M. Lee, J. Park, K. H. Jeon et al., "Efficacy of short-term high-dose statin pretreatment in prevention of contrast- 
induced acute kidney injury: updated study-level metaanalysis of 13 randomized controlled trials," PLoS One, vol. 9, no. 11, article e111397, 2014.

[84] C. Quintavalle, D. Fiore, F. de Micco et al., "Impact of a high loading dose of atorvastatin on contrast-induced acute kidney injury," Circulation, vol. 126, no. 25, pp. 3008-3016, 2012.

[85] J. H. Park, J. K. Shim, J. W. Song, S. Soh, and Y. L. Kwak, "Effect of atorvastatin on the incidence of acute kidney injury following valvular heart surgery: a randomized, placebocontrolled trial," Intensive Care Medicine, vol. 42, no. 9, pp. 1398-1407, 2016.

[86] J. Wang, C. Gu, M. Gao, W. Yu, and Y. Yu, "Preoperative Statin Therapy and Renal Outcomes After Cardiac Surgery: A Meta- analysis and Meta-regression of 59,771 Patients," The Canadian Journal of Cardiology, vol. 31, no. 8, pp. 1051-1060, 2015.

[87] P. Kandula, "Statins in perioperative prevention of acute kidney injury in patients undergoing cardiac surgery," European Heart Journal, vol. 30, no. 2, p. 250, 2009.

[88] F. T. Billings 4th, S. K. Ball, L. J. Roberts 2nd, and M. Pretorius, "Postoperative acute kidney injury is associated with hemoglobinemia and an enhanced oxidative stress response," Free Radical Biology \& Medicine, vol. 50, no. 11, pp. 1480-1487, 2011.

[89] I. C. Vermeulen Windsant, M. G. Snoeijs, S. J. Hanssen et al., "Hemolysis is associated with acute kidney injury during major aortic surgery," Kidney International, vol. 77, no. 10, pp. 913-920, 2010.

[90] M. Haase, A. Haase-Fielitz, S. M. Bagshaw, C. Ronco, and R. Bellomo, "Cardiopulmonary bypass-associated acute kidney injury: a pigment nephropathy?," Contributions to Nephrology, vol. 156, pp. 340-353, 2007.

[91] P. Hu, Y. Chen, Y. Wu et al., "Development and validation of a model for predicting acute kidney injury after cardiac surgery in patients of advanced age," Journal of Cardiac Surgery, vol. 36, no. 3, pp. 806-814, 2021.

[92] H. Lin, J. Hou, H. Tang et al., "A novel nomogram to predict perioperative acute kidney injury following isolated coronary artery bypass grafting surgery with impaired left ventricular ejection fraction," BMC Cardiovascular Disorders, vol. 20, no. 1, p. 517, 2020.

[93] R. H. Mehta, J. D. Grab, S. M. O’Brien et al., "Bedside tool for predicting the risk of postoperative dialysis in patients undergoing cardiac surgery," Circulation, vol. 114, no. 21, pp. 2208-2216, 2006.

[94] C. V. Thakar, S. Arrigain, S. Worley, J. P. Yared, and E. P. Paganini, "A clinical score to predict acute renal failure after cardiac surgery," Journal of the American Society of Nephrology, vol. 16, no. 1, pp. 162-168, 2005.

[95] D. N. Wijeysundera, K. Karkouti, J. Y. Dupuis et al., "Derivation and validation of a simplified predictive index for renal replacement therapy after cardiac surgery," JAMA, vol. 297, no. 16, pp. 1801-1809, 2007.

[96] L. Englberger, R. M. Suri, Z. Li et al., "Validation of clinical scores predicting severe acute kidney injury after cardiac surgery," American Journal of Kidney Diseases, vol. 56, no. 4, pp. 623-631, 2010.

[97] P. B. Rahmanian, F. Filsoufi, J. G. Castillo et al., "Predicting postoperative renal failure requiring dialysis, and an analysis of long-term outcome in patients undergoing valve surgery,"
The Journal of Heart Valve Disease, vol. 17, no. 6, pp. 657665, 2008.

[98] S. Aronson, M. L. Fontes, Y. Miao, and D. T. Mangano, "Risk index for perioperative renal dysfunction/failure: critical dependence on pulse pressure hypertension," Circulation, vol. 115, no. 6, pp. 733-742, 2007.

[99] J. R. Brown, R. P. Cochran, B. J. Leavitt et al., "Multivariable prediction of renal insufficiency developing after cardiac surgery," Circulation, vol. 116, 11 Suppl, pp. I139I143, 2007.

[100] H. Palomba, I. de Castro, A. L. Neto, S. Lage, and L. Yu, "Acute kidney injury prediction following elective cardiac surgery: AKICS score," Kidney International, vol. 72, no. 5, pp. 624-631, 2007.

[101] J. A. Neyra, M. C. Hu, A. Minhajuddin et al., "Kidney tubular damage and functional biomarkers in acute kidney injury following cardiac surgery," Kidney International Reports, vol. 4, no. 8, pp. 1131-1142, 2019.

[102] P. Devarajan, C. D. Krawczeski, M. T. Nguyen, T. Kathman, Z. Wang, and C. R. Parikh, "Proteomic identification of early biomarkers of acute kidney injury after cardiac surgery in children," American Journal of Kidney Diseases, vol. 56, no. 4, pp. 632-642, 2010.

[103] D. S. Cooper, D. Claes, S. L. Goldstein et al., "Follow-up renal assessment of injury long-term after acute kidney injury (FRAIL-AKI)," Clinical Journal of the American Society of Nephrology, vol. 11, no. 1, pp. 21-29, 2016.

[104] T. Moriyama, S. Hagihara, T. Shiramomo, M. Nagaoka, S. Iwakawa, and Y. Kanmura, "Comparison of three early biomarkers for acute kidney injury after cardiac surgery under cardiopulmonary bypass," Journal of Intensive Care, vol. 4, no. 1, p. 41, 2016.

[105] L. Dong, Q. Ma, M. Bennett, and P. Devarajan, "Urinary biomarkers of cell cycle arrest are delayed predictors of acute kidney injury after pediatric cardiopulmonary bypass," Pediatric Nephrology, vol. 32, no. 12, pp. 2351-2360, 2017.

[106] M. Haase and A. Haase-Fielitz, "Can novel biomarkers complement best possible clinical assessment for early acute kidney injury diagnosis? ${ }^{\bigotimes, " ~ J o u r n a l ~ o f ~ t h e ~ A m e r i c a n ~ C o l l e g e ~ o f ~}$ Cardiology, vol. 58, no. 22, pp. 2310-2312, 2011.

[107] C. R. Parikh, J. Mishra, H. Thiessen-Philbrook et al., "Urinary IL-18 is an early predictive biomarker of acute kidney injury after cardiac surgery," Kidney International, vol. 70, no. 1, pp. 199-203, 2006.

[108] M. Küllmar, K. Saadat-Gilani, R. Weiss et al., "Kinetic changes of plasma renin levels predict acute kidney injury in cardiac surgery patients," American Journal of Respiratory and Critical Care Medicine, 2020.

[109] J. H. Greenberg, M. Zappitelli, Y. Jia et al., "Biomarkers of AKI progression after pediatric cardiac surgery," Journal of the American Society of Nephrology, vol. 29, no. 5, pp. 15491556, 2018.

[110] C. A. de Fontnouvelle, J. H. Greenberg, H. R. Thiessen-Philbrook et al., "Interleukin-8 and tumor necrosis factor predict acute kidney injury after pediatric cardiac surgery," The Annals of Thoracic Surgery, vol. 104, no. 6, pp. 2072-2079, 2017.

[111] C. Stoppe, L. Averdunk, A. Goetzenich et al., "The protective role of macrophage migration inhibitory factor in acute kidney injury after cardiac surgery," Science Translational Medicine, vol. 10, no. 441, article eaan4886, 2018. 
[112] S. V. Shah, M. M. Rajapurkar, and R. Baliga, "The role of catalytic iron in acute kidney injury," Clinical Journal of the American Society of Nephrology, vol. 6, no. 10, pp. 23292331, 2011.

[113] M. Haase, R. Bellomo, and A. Haase-Fielitz, "Novel biomarkers, oxidative stress, and the role of labile iron toxicity in cardiopulmonary bypass-associated acute kidney injury," Journal of the American College of Cardiology, vol. 55, no. 19, pp. 2024-2033, 2010.

[114] J. Ho, M. Lucy, O. Krokhin et al., "Mass spectrometry-based proteomic analysis of urine in acute kidney injury following cardiopulmonary bypass: a nested case-control study," American Journal of Kidney Diseases, vol. 53, no. 4, pp. 584-595, 2009.

[115] F. Petronilho, L. Constantino, B. de Souza et al., "Efficacy of the combination of $\mathrm{N}$-acetylcysteine and desferrioxamine in the prevention and treatment of gentamicin-induced acute renal failure in male Wistar rats," Nephrology, Dialysis, Transplantation, vol. 24, no. 7, pp. 2077-2082, 2009.

[116] S. Palipoch, "A review of oxidative stress in acute kidney injury: protective role of medicinal plants-derived antioxidants," African Journal of Traditional, Complementary, and Alternative Medicines, vol. 10, no. 4, pp. 88-93, 2013.

[117] S. Xu, Y. H. Chen, Z. X. Tan et al., "Vitamin D3 pretreatment alleviates renal oxidative stress in lipopolysaccharide-induced acute kidney injury," The Journal of Steroid Biochemistry and Molecular Biology, vol. 152, pp. 133-141, 2015.

[118] N. N. Patel, T. Toth, C. Jones et al., "Prevention of postcardiopulmonary bypass acute kidney injury by endothelin A receptor blockade," Critical Care Medicine, vol. 39, no. 4, pp. 793-802, 2011.

[119] A. X. Garg, P. J. Devereaux, S. Yusuf et al., "Kidney function after off-pump or on-pump coronary artery bypass graft surgery: a randomized clinical trial," JAMA, vol. 311, no. 21, pp. 2191-2198, 2014.

[120] P. Sidaway, "IgG reactivity to apoptotic cells-role in presensitization revealed," Nature Reviews. Nephrology, vol. 10, no. 8, p. 423, 2014.

[121] V. F. Seabra, S. Alobaidi, E. M. Balk, A. H. Poon, and B. L. Jaber, "Off-pump coronary artery bypass surgery and acute kidney injury: a meta-analysis of randomized controlled trials," Clinical Journal of the American Society of Nephrology, vol. 5, no. 10, pp. 1734-1744, 2010.

[122] M. Vives, G. Lockwood, P. P. Punjabi, and D. Krahne, "Neutrophil gelatinase-associated lipocalin and acute kidney injury after cardiac surgery," Anesthesiology, vol. 116, no. 2, pp. 490-491, 2012.

[123] J. Ho, M. Reslerova, B. Gali et al., "Urinary hepcidin-25 and risk of acute kidney injury following cardiopulmonary bypass," Clinical Journal of the American Society of Nephrology, vol. 6, no. 10, pp. 2340-2346, 2011.

[124] T. Mayer, D. Bolliger, M. Scholz et al., "Urine biomarkers of tubular renal cell damage for the prediction of acute kidney injury after cardiac surgery-a pilot study," Journal of Cardiothoracic and Vascular Anesthesia, vol. 31, no. 6, pp. 20722079, 2017.

[125] N. Kim, S. Y. Dai, V. Pang, and C. D. Mazer, "Vasopressinase activity: a potential early biomarker for detecting cardiopulmonary bypass-associated acute kidney injury?," The Thoracic and Cardiovascular Surgeon, vol. 64, no. 7, pp. 555-560.
[126] R. Wald, O. Liangos, M. C. Perianayagam et al., "Plasma cystatin $\mathrm{C}$ and acute kidney injury after cardiopulmonary bypass," Clinical Journal of the American Society of Nephrology, vol. 5, no. 8, pp. 1373-1379, 2010.

[127] A. B. Hassinger, M. S. Wainwright, J. C. Lane, S. Haymond, C. L. Backer, and E. Wald, "Elevated preoperative serum asymmetrical dimethylarginine (ADMA) is associated with poor outcomes after pediatric cardiac surgery," Intensive Care Medicine, vol. 38, no. 10, pp. 1697-1704, 2012.

[128] N. Sullo, S. Mariani, M. JnTala et al., "An observational cohort feasibility study to identify microvesicle and microRNA biomarkers of acute kidney injury following pediatric cardiac surgery," Pediatric Critical Care Medicine, vol. 19, no. 9, pp. 816-830.

[129] R. Wu, Y. Wu, L. Yang, Y. Deng, and D. Chen, "Value of serum level of microRNA-494 in predicting prognosis of acute renal injury after cardiac surgery in children," Zhonghua Wei Zhong Bing Ji Jiu Yi Xue, vol. 31, no. 12, pp. 1469-1473. 